\title{
Treatment of limited disease small cell lung cancer: the multidisciplinary team
}

\author{
Markus Glatzer ${ }^{1}$, Achim Rittmeyer ${ }^{2}$, Joachim Müller ${ }^{3}$, Isabelle Opitz ${ }^{4}$, \\ Alexandros Papachristofilou ${ }^{5}$, Ioannis Psallidas ${ }^{6,7}$, Martin Früh $^{8}$, Diana Born ${ }^{9}$ \\ and Paul Martin Putora'
}

Number 7 in the series "Multidisciplinary questions in thoracic oncology: the team experience"

Edited by J-P. Sculier

\begin{abstract}
Affiliations: 'Dept of Radiation Oncology, Kantonsspital St Gallen, St Gallen, Switzerland. ${ }^{2}$ Dept of Thoracic Oncology, Lungenfachklinik Immenhausen, Immenhausen, Germany. ${ }^{3}$ Dept of Radiology and Nuclear Medicine, Kantonsspital St Gallen, St Gallen, Switzerland. "'Dept of Thoracic Surgery, University Hospital Zürich, Zürich, Switzerland. ${ }^{5}$ Dept of Radiation Oncology, University Hospital Basel, Basel, Switzerland. ${ }^{6}$ Oxford Centre for Respiratory Medicine, Churchill Hospital, Oxford, UK. ${ }^{7}$ Oxford Respiratory Trials Unit, Churchill Hospital, Oxford, UK. ${ }^{8}$ Dept of Oncology and Haematology, Kantonsspital St Gallen, St Gallen, Switzerland. ${ }^{9}$ Institute of Pathology, Kantonsspital St Gallen, St Gallen, Switzerland.
\end{abstract}

Correspondence: Markus Glatzer, Dept of Radiation Oncology, Kantonsspital St Gallen, 9007 St Gallen, Switzerland. E-mail: markus.glatzerakssg.ch

@ERSpublications

Small cell lung cancer treatment is multifaceted and requires close collaboration within a multidisciplinary team http://ow.ly/A6FO30c4bts

Cite this article as: Glatzer M, Rittmeyer A, Müller J, et al. Treatment of limited disease small cell lung cancer: the multidisciplinary team. Eur Respir J 2017; 50: 1700422 [https://doi.org/10.1183/ 13993003.00422-2017].

ABSTRACT Small cell lung cancer (SCLC) presents multiple interdisciplinary challenges with several paradigm shifts in its treatment in recent years. SCLC treatment requires multidisciplinary management and timely treatment. The aim of this review is to focus on the team management aspects in the treatment of limited disease SCLC and how this can contribute towards improving outcomes.

Received: Aug 172016 | Accepted after revision: May 162017

Previous articles in this series: No. 1: Malhotra J, Malvezzi M, Negri E, et al. Risk factors for lung cancer worldwide. Eur Respir J 2016; 48: 889-902. No. 2: McDonald F, De Waele M, Hendriks LEL, et al. Management of stage I and II nonsmall cell lung cancer. Eur Respir J 2017; 49: 1600764. No. 3: Leduc C, Antoni D, Charloux A, et al. Comorbidities in the management of patients with lung cancer. Eur Respir J 2017; 49: 1601721. No. 4: Zugazagoitia J, Molina-Pinelo S, Lopez-Rios F, et al. Biological therapies in nonsmall cell lung cancer. Eur Respir J 2017; 49: 1601520. No. 5: Calvayrac O, Pradines A, Pons E, et al. Molecular biomarkers for lung adenocarcinoma. Eur Respir J 2017; 49: 1601734. No. 6: Meert A-P, Grigoriu B, Licker M, et al. Intensive care in thoracic oncology. Eur Respir J 2017; 49: 1602189.

Conflict of interest: None declared.

Copyright OERS 2017 


\section{Introduction}

Limited disease small cell lung cancer (LD-SCLC) is a potentially curable disease that requires timely coordination of efforts from multiple disciplines. The multidisciplinary team (MDT) meeting is an ideal forum and starting point to discuss each patient in consideration of relevant information from the perspective of all involved specialists.

\section{Role of multidisciplinary teams}

MDTs have a long and complex history; they co-developed with educational sessions, regular collaboration among specialists and tumour boards $[1,2]$. An MDT meeting is a meeting of a group of people from different healthcare disciplines at a given time to discuss individual patients [3].

Simple organisational versions are based on a unidisciplinary team. These usually consist of the patient, primary treating physician and one or more specialists. Decisions in these teams are often dominated by a single individual. MDTs arise by participation of further specialists and include perspectives from the different disciplines in the decision-making process. Ideally, a transdisciplinary team develops, as described in the continuum model [4]. In a well-working transdisciplinary team cooperation is automatic and barriers between disciplines are removed. Recommendations are based on interdisciplinary insights instead of hierarchical structures. Core team members communicate closely and involve a multitude of other agents, e.g. general practitioners, social workers, physiotherapists, administrators, clinical trial specialists and nurses, to achieve the best possible results for the patient $[1,5,6]$.

The aim of MDTs is to improve cancer care, although in lung cancer evidence demonstrating a clear survival benefit is controversial [3,7-9], and evidence is even scarcer for SCLC. Several trials reported outcomes before and after the implementation of MDTs; only three of these included a small number of patients with SCLC [10-12]. A systematic review by Coory et al. [3] identified only one randomised trial [13] including SCLC investigating the impact of MDTs. Despite lacking evidence for SCLC, evidence from breast, head-and-neck and rectal cancer has demonstrated that MDTs can reduce rates of positive surgical margins, reduce costs, improve patient satisfaction, improve documentation regarding TNM (tumour, nodes, metastasis) staging or performance status and even decrease the time from diagnosis to treatment [5, 14-17].

The time factor in particular is very important in SCLC where fast-track procedures should be considered [1]. Without treatment, patients with SCLC rarely survive longer than a few weeks to months [5]. Insufficient or late treatments have been associated with poor outcomes [18-20].

Having multiple specialists involved early enables them to anticipate problems or address issues ahead. PRADES et al. [9] hit the mark: "the rationale behind the more comprehensive structuring of teamwork in cancer care goes beyond eventual clinical outcomes and embraces the process of care as a whole". Spatial issues should not be a limiting factor nowadays; depending on the setting, a telecommunication solution might be implemented when physical meetings are difficult [12].

Tumour boards have now developed into multidisciplinary platforms for care teams which, ideally in agreement, recommend further diagnosis and management, take responsibility for these recommendations, and implement them in close partnership with the patient [21]. Tumour boards are established in most hospitals across Europe; however, wide variations of implementation and organisational details exist [6]. These variations, or lack of implementation, are even larger across the world [22]. The European Respiratory Society and the American Thoracic Society have declared tumour boards the standard of care [23].

Although referral practice may vary $[24,25]$, the basic steps shown in figure 1 are generally followed in the typical management of SCLC.

\section{From symptoms to diagnosis: the multidisciplinary approach}

About $30 \%$ of patients will present with LD-SCLC at the time of diagnosis [26-28]. Owing to the high proliferation rate of this tumour type, time should not be wasted. Patients often present to physicians with various symptoms, including paraneoplastic syndromes [29]. Potentially, not every clinician will identify all symptoms properly or be able to initiate the correct first steps; however, with proper presentation and the expertise of an MDT, relevant problems can be identified and approached.

The goal of diagnostics is to establish the underlying disease and precisely define the tumour stage of SCLC; this is the basis for the subsequent treatment recommendation by the MDT. Statements from the radiation oncologist or surgeon regarding potential local treatments may impact the type of diagnostics being performed and this also applies to information about patient preference or suitability of lesions for potential biopsies. Multiple diagnostic modalities are available, such as multidetector computed tomography $(\mathrm{CT})$, positron emission tomography (PET)/CT, magnetic resonance imaging (MRI), PET/MRI, endobronchial ultrasound (EBUS)-guided fine needle aspiration and bone scanning [30]. Although the 
Level of knowledge
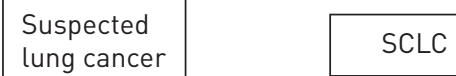

LD-SCLC

Response to residual disease

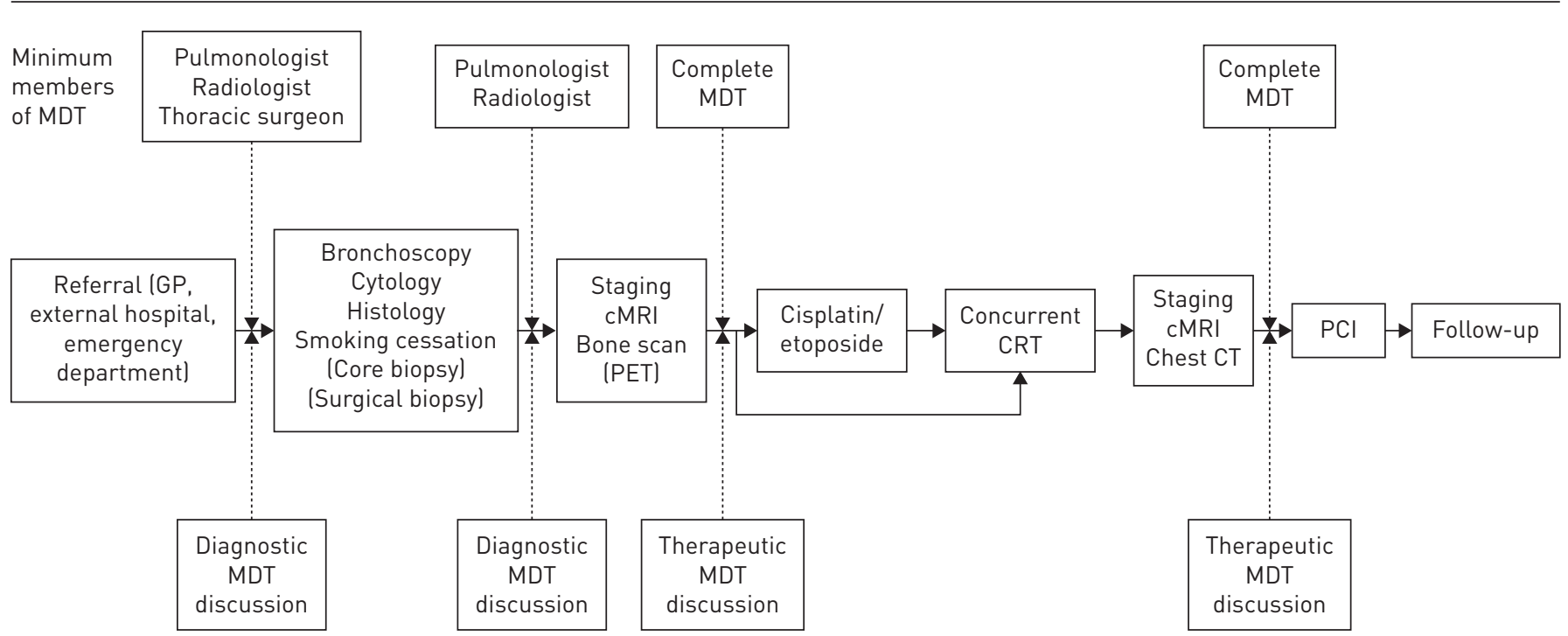

FIGURE 1 Basic steps in the management of small cell lung cancer (SCLC). LD: limited disease; MDT: multidisciplinary team; GP: general practitioner; cMRI: cranial magnetic resonance imaging; PET: positron emission tomography; CRT: chemoradiotherapy; CT: computed tomography; PCl: prophylactic cranial irradiation.

sensitivity and specificity of imaging is improving, histopathological diagnosis is not obsolete. In an MDT it is the task of the radiology and nuclear medicine specialists to show and interpret their results and facilitate their correct interpretation. Conclusions are best drawn by considering all available data, and the team requires information beyond imaging and histology, including patient information (e.g. smoking history and geographical background) and/or clinical expertise (e.g. considerations on differential diagnoses by the respiratory physician).

Although outdated, SCLC is still commonly staged using the Veterans Administration Lung Study Group system [31]. LD-SCLC means that the cancer is confined to one hemi-thorax, all of which can be encompassed in a safe radiotherapy field. The seventh edition of the Union for International Cancer Control TNM Classification of Malignant Tumours (2009) as well as the updated eighth edition (2016) recommend the use of the TNM classification for staging SCLC, which also has a demonstrated prognostic value [32, 33]. LD-SCLC now corresponds to T1-4 N0-3 M0 tumours, whereas metastatic tumours encompass former extensive disease (ED-SCLC).

Histological confirmation should always be sought in a timely fashion [34, 35]. The rate of pathological tissue confirmation is higher among patients discussed at an MDT [24]; however, obtaining tissue samples can be challenging and may require multiple specialities [36]. The team should ensure that the most conveniently accessible site with the highest chance of obtaining tissue is targeted first, minimising the risk of repetitive procedures [37]. Potential side-effects should be considered individually for each patient (e.g. the risk of pneumothorax based on lung imaging). CT and PET/CT images can provide a valuable basis for determining the best strategy, which may include various combinations of imaging and external biopsies and/or transbronchial or surgical approaches, making interdisciplinary exchange essential $[26,38,39]$.

Once tissue samples have been retrieved, histological evaluation can be challenging due to differential diagnoses [26, 40-43]. Information on a history of inflammation or the presence of other malignancies such as lymphoma is crucial to the pathologist and is essential information that must be communicated. SCLC can present as an extensively necrotic neoplasm, making histological diagnosis difficult. Biopsies should take details of imaging into account and provide a good opportunity to include a broad team in the process. Depending on local practice, the pathologists may be actively involved in obtaining biopsies. Pathologists can be pivotal in differentiating recurrence from a new primary or a metastasis from a different neoplasm, with a major impact on treatment decisions.

Mediastinal staging is recommended before curative treatment [44]. EBUS bronchoscopy is preferred for the staging of mediastinal lymph nodes. Mediastinoscopy can be used to sample mediastinal lymph nodes 
not accessible with EBUS or with inconclusive results [45]. The pulmonologist, thoracic surgeon and imaging specialist should all be involved in mediastinal staging.

Since in most institutions MDT meetings will occur once a week, potential delays in the management of SCLC need to be weighed against the advantages of such meetings. The MDT should be involved throughout the patient pathway, before and after the meeting, especially when treatment is initiated in an acute setting. Relevant information needs to be available for the MDT and the questions to the board should always be specific [1]; this might seem obvious, but all of the current co-authors have experienced otherwise. The results should be well documented and communicated $[20,46]$.

On average, the time from the first abnormal radiological finding to the first day of treatment in all lung cancer patients is $\sim 2.5$ months $[47,48]$, which may be deleterious in this fast-growing tumour. After therapy is proposed, initiation of radical treatment in lung cancer involving radiotherapy or surgery usually requires 2-3 weeks [24]. In SCLC, in particular, there are some scenarios demanding rapid introduction of therapy, such as vena cava superior syndrome or syndrome of inappropriate antidiuretic hormone. The most intense teamwork is required in the first days when diagnosis and staging are performed and the first treatment initiated. Treatment start within 1-2 weeks after suspected SCLC should be pursued. This is even more important for symptomatic patients.

\section{Breaking bad news}

Receiving a diagnosis of lung cancer can be devastating, and many patients are left with feelings of hopelessness and uncertainty about the future. Accurate and sensitively delivered information is crucial and, next to physicians, lung cancer specialist nurses are a valuable resource in this regard. Nurses act as key workers, offering practical and emotional support, and providing a consistent presence at clinic appointments. This support is critical not at a single time-point, but throughout the process of diagnosis and beyond [49]. Their role throughout the multidisciplinary process should not be underestimated. Psycho-oncologists should also be integrated very early in the disease course, especially for teaching in self-coping strategies, one of the key factors that enable the patient to adapt to distress, leading to a better quality of life [50].

\section{Coordinating treatment \\ Radiochemotherapy}

Once the diagnosis of LD-SCLC is established the standard treatment for fit patients will be concurrent radiochemotherapy [39], but chemotherapy is often initiated first to rapidly counter the fast-growing tumour [35]. Chemotherapy should commence without delay after the tumour board decision. SCLC is a chemo-sensitive tumour and a rapid response is often observed. Even in urgent situations with vena cava superior syndrome [51] rapid initiation of chemotherapy is preferred over interventional radiological treatment [52], yet both should be evaluated. In the meantime, preparation for radiotherapy should be initiated $[26,39]$.

The current standard chemotherapy regime for ED- and LD-SCLC in the Western world consists of four to six cycles of platinum and etoposide [26]. Combination therapies have been shown to be superior to single-agent treatment $[53,54]$.

Historically, twice-daily and once-daily radiotherapy regimes have evolved for SCLC side-by-side [55-61]. SCLC can be treated with daily radiotherapy (to $66 \mathrm{~Gy}$ ) or with twice-daily treatment (to $45 \mathrm{~Gy}$ ), both with a relatively favourable 3 -year survival rate of $\sim 40 \%$ and similar toxicity rates [62]. Patient preference should be accommodated when choosing among these regimes; the decision may be influenced by factors such as availability of transportation.

Two meta-analyses demonstrated that concurrent radiochemotherapy improved survival [39, 63, 64]. In addition to an absolute gain of $5 \%$ in overall survival at 5 years (23.7\% versus $18.3 \%$ ) with concomitant radiochemotherapy [65], it is important to evaluate the general condition of the patient. The expected survival benefit needs to be weighed against potential increased toxicity [59, 65]. The decision for either should be met by an MDT considering the overall performance status, age and comorbidities of the patient. Typically, multiple disciplines are involved during radiochemotherapy; side-effects such as neutropenic fever, pneumonia or oesophagitis require rapid and precise communication to initiate timely counter-measures and potentially adapt treatments, avoiding unnecessary treatment breaks. It should be noted that age alone should not be considered a prohibiting factor to concurrent treatment [66].

Despite controversial findings in the literature [67-69], most data and guidelines support early thoracic radiotherapy beginning with the first or second cycle when cisplatin-based chemotherapy is used [26, 39, $68,70-72]$, as the majority of studies indicate a benefit with early radiotherapy [73]. 
In some cases radiotherapy may be considered too toxic due to the extent of the disease and pre-treatment assessment [38, 74]. Transdisciplinary teamwork is important between radiologists and radiation oncologists to ensure correct volume definition. If the treatment volume remains too extensive then delaying radiotherapy after an initial shrinking of the tumour may be a viable option.

Various factors influence treatments, including insurance status, availability of technology, professional and patient preference, or even rural or urban location [75]. A review in the Commonwealth of Kentucky in the USA demonstrated utilisation of radiochemotherapy in approximately two-thirds of LD-SCLC patients [76], which corresponds to other reported utilisation rates [77, 78], despite a relatively high proportion of rural settings. Although clear evidence is difficult to obtain, the improvements in outcome in LD-SCLC in recent decades are being attributed to higher utilisation rates of active or multimodal treatment $[76,79]$, which is at least partially facilitated by MDTs $[80,81]$.

\section{Prophylactic cranial irradiation}

The risk of brain metastases can be nearly halved in LD-SCLC with the use of prophylactic cranial irradiation (PCI) [82-85]. PCI is favourable for patients with at least stable disease after radiochemotherapy, demonstrating a significant improvement in overall survival [86]. Response evaluation should be interdisciplinary, including the treating clinicians and imaging specialists. Close communication is required to avoid confusing radiation-induced changes with progressive disease. Cranial MRI before PCI should be considered as it identifies patients who might require therapeutic whole-brain radiotherapy (with a higher dose) for brain metastases [87]. Before initiating PCI, prognostic factors such as performance status, age, life expectancy and comorbidities need to be considered and presented in the MDT meetings by the treating clinicians. Advanced age only should not rule out PCI [88].

The risk for neurocognitive decline after PCI has been reported as 30-60\% after 1 year [85, 89-91], depending on the measure of neurocognitive impairment. Patients at higher risk for neurocognitive deterioration (e.g. with diabetes or pre-existing cerebrovascular problems) [92-94] should be critically evaluated, involving neurologists for neurocognitive assessments. An important region for neurocognitive function is located in the hippocampus and current research includes investigating hippocampal-sparing cranial irradiation to reduce neurocognitive dysfunction $[95,96]$.

In addition to neurocognitive dysfunction, hair loss is another detrimental side-effect. Patients have to be prepared for hair loss, potentially with the help of psycho-oncologists, to minimise the impact on quality of life. When PCI is not implemented, close follow-up with cranial MRI should be performed if therapeutic radiotherapy would be an option [97].

\section{Lifestyle modification}

Lifestyle modification can also improve outcomes. SCLC represented $17 \%$ of lung cancer cases in the USA in 1986 and declined to $13 \%$ in 2002, likely attributed to changes in smoking behaviour [98]. Outcomes are improved even when smoking is stopped after diagnosis [99, 100]. Multidisciplinary lung cancer treatment programmes offer an ideal environment to optimally deliver effective smoking cessation services. Smoking cessation should be offered utilising the services of dedicated smoking cessation programmes and tailoring cessation interventions to the patient's cancer treatment plan [101].

\section{Individual treatment approaches \\ Surgery}

Surgery can be considered for several indications in SCLC patients: in localised disease, for mixed histological tumour types, for salvage resection for persistent local disease after radiochemotherapy and for early locally relapsed (potentially chemo-resistant) tumours [102]. Recent analyses of the SEER (Surveillance, Epidemiology and End Results) database (seer.cancer.gov) also, with limitations, suggest that surgery may be appropriate for some patients with localised disease [82, 83].

Despite these uncertainties, surgery is an option for T1-2 N0 SCLC in current guidelines after appropriate staging $[26,103]$. It is important that surgical resection and its potential extent are discussed in an MDT, bringing this option to attention.

Before radical treatment, interdisciplinary cardiopulmonary function testing of the patient should be performed [74], including pulmonologists and nuclear medicine specialists for evaluation of lung function, surgeons estimating the extent of surgery, and anaesthesiologists evaluating operability.

Lobectomy is favoured over segmental or wedge resections; obviously, an R0 (complete excision) needs to be achieved [39]. 
Evidence for the use of PCI after complete resection of SCLC is limited. However, PCI should be discussed by the MDT [104].

\section{Adjuvant treatment}

After resection, further therapy has to be discussed with all involved specialists, including pathologists, radiologists, oncologist, surgeons and radiation oncologists. With a high risk of loco-regional recurrence, surgery alone is not sufficient [105]. Adjuvant chemotherapy is recommended even in patients with pN0 lymph node status $[106,107]$. In the case of positive nodes, post-operative radiation therapy should also be discussed [108, 109].

The decision should be made considering performance status, age, lung function, comorbidities and extent of disease, and with close collaboration between pulmonologists, surgeons and pathologists. In case of an inadequate resection margin (R1), the involved surgeon and the pathologist support the radiation oncologist in defining the target if radiotherapy is indicated.

\section{Novel treatment approaches}

Whether immunotherapy improves outcomes in LD-SCLC is currently under investigation. The MDT provides a good platform to present ongoing trials to colleagues of other disciplines and to select patients for whom trial participation can be proposed. Patients who are seen by MDT members have a higher enrolment rate in clinical trials [110]. The support of a study nurse cannot be underestimated, to the patient as well as the treating physicians.

\section{Follow-up}

High recurrence rates justify follow-up. Follow-up includes contrast-enhanced CT [26, 39, 111]. The aim of close follow-up is early detection of recurrence in a stage where patients still have a good performance status and localised disease. Next to imaging, smoking cessation should be actively discussed. Although plasma progastrin-releasing peptide with or without neuron-specific enolase measurements may be a useful diagnostic marker to detect early recurrence [112-115], prospective trials evaluating the benefit are lacking and therefore routine tumour marker assessment is not recommended in this setting.

Any form of suspected recurrence should be discussed in an interdisciplinary setting; post-radiotherapy changes in the lung might need interpretation. Histological verification may exclude a second primary tumour which could be treated in a potentially curative manner. Second-line treatments are at least as multidisciplinary as the primary treatment. Referral to palliative care services among patients who were discussed at tumour boards is higher, suggesting that symptom control and quality of life can be better addressed in an MDT setting [7].

Follow-up also serves to detect and treat treatment-related side-effects. Depending on the setting, follow-up is often performed by a single specialist. Feedback to the MDT and cooperation is crucial for correct interpretation and treatment.

\section{Summary}

SCLC is a rapidly growing tumour with poor prognosis, even in LD-SCLC. Optimal treatment involves timely concurrent radiochemotherapy and prophylactic brain irradiation in most patients. For this to be delivered optimally, diagnosis and staging need to be well coordinated, timely and accurate. Well-organised interdisciplinary collaboration is essential to facilitate adequate treatment considering all aspects of care, including patient preference.

\section{References}

1 Powell HA, Baldwin DR. Multidisciplinary team management in thoracic oncology: more than just a concept? Eur Respir J 2014; 43: 1776-1786.

2 Gross GE. The role of the tumor board in a community hospital. CA Cancer J Clin 1987; 37: 88-92.

3 Coory M, Gkolia P, Yang I, et al. Systematic review of multidisciplinary teams in the management of lung cancer. Lung Cancer 2008; 60: 14-21.

4 NHS England. MDT Development: Working Toward an Effective Multidisciplinary/Multiagency Team. Leeds, NHS England, 2015.

5 Kato Y, Ferguson TB, Bennett DE, et al. Oat cell carcinoma of the lung: a review of 138 cases. Cancer 1969; 23: 517-524.

6 Blum TG, Rich A, Baldwin D, et al. The European initiative for quality management in lung cancer care. Eur Respir J 2014; 43: 1254-1277.

7 Boxer MM, Vinod SK, Shafiq J, et al. Do multidisciplinary team meetings make a difference in the management of lung cancer? Cancer 2011; 117: 5112-5120.

8 Bydder S, Nowak A, Marion K, et al. The impact of case discussion at a multidisciplinary team meeting on the treatment and survival of patients with inoperable non-small cell lung cancer. Intern Med J 2009; 39: 838-841. 

outcomes. Health Policy 2015; 119: 464-474.

10 Bowen E, Anderson J, Roddie M. Improving surgical resection rates in lung cancer without a two stop service. Thorax 2003; 58: 368-368.

11 Dillman RO, Chico SD. Cancer patient survival improvement is correlated with the opening of a community cancer center: comparisons with intramural and extramural benchmarks. J Oncol Pract 2005; 1: 84-92.

12 Davison A, Eraut C, Haque A, et al. Telemedicine for multidisciplinary lung cancer meetings. $J$ Telemed Telecare 2004; 10: 140-143.

13 Murray P, O’Brien M, Sayer R, et al. The pathway study: results of a pilot feasibility study in patients suspected of having lung carcinoma investigated in a conventional chest clinic setting compared to a centralised two-stop pathway. Lung Cancer 2003; 42: 283-290.

14 Burton S, Brown G, Daniels IR, et al. MRI directed multidisciplinary team preoperative treatment strategy: the way to eliminate positive circumferential margins? Br J Cancer 2006; 94: 351-357.

15 Westin T, Stalfors J. Tumour boards/multidisciplinary head and neck cancer meetings: are they of value to patients, treating staff or a political additional drain on healthcare resources? Curr Opin Otolaryngol Head Neck Surg 2008; 16: 103-107.

16 Birchall M, Bailey D, King P, et al. Effect of process standards on survival of patients with head and neck cancer in the south and west of England. Br J Cancer 2004; 91: 1477-1481.

17 Gabel M, Hilton NE, Nathanson SD. Multidisciplinary breast cancer clinics. Do they work? Cancer 1997; 79: 2380-2384.

18 Billing J, Wells F. Delays in the diagnosis and surgical treatment of lung cancer. Thorax 1996; 51: 903-906.

19 Fergusson R, Gregor A, Dodds R, et al. Management of lung cancer in South East Scotland. Thorax 1996; 51: 569-574.

20 Brown JS, Eraut D, Trask C, et al. Age and the treatment of lung cancer. Thorax 1996; 51: 564-568.

21 Fennell ML, Das IP, Clauser S, et al. The organization of multidisciplinary care teams: modeling internal and external influences on cancer care quality. J Natl Cancer Inst Monogr 2010; 2010: 72-80.

22 Song $\mathrm{P}, \mathrm{Wu} \mathrm{Q}$, Huang Y. Multidisciplinary team and team oncology medicine research and development in China. Biosci Trends 2010; 4: 152-160.

23 Gaga M, Powell CA, Schraufnagel DE, et al. An official American Thoracic Society/European Respiratory Society statement: the role of the pulmonologist in the diagnosis and management of lung cancer. Am J Respir Crit Care Med 2013; 188: 503-507.

24 Conron M, Phuah S, Steinfort D, et al. Analysis of multidisciplinary lung cancer practice. Intern Med J 2007; 37: $18-25$.

25 Deegan PC, Heath L, Brunskill J, et al. Reducing waiting times in lung cancer. J Royal Coll Phys Lond 1997; 32: 339-343.

26 Früh M, De Ruysscher D, Popat S, et al. Small-cell lung cancer (SCLC): ESMO Clinical Practice Guidelines for diagnosis, treatment and follow-up. Ann Oncol 2013; 24: Suppl. 6, vi99-vi105.

27 Lortet-Tieulent J, Soerjomataram I, Ferlay J, et al. International trends in lung cancer incidence by histological subtype: adenocarcinoma stabilizing in men but still increasing in women. Lung Cancer 2014; 84: 13-22.

28 Murray N, Coy P, Pater JL, et al. Importance of timing for thoracic irradiation in the combined modality treatment of limited-stage small-cell lung cancer. The National Cancer Institute of Canada Clinical Trials Group. J Clin Oncol 1993; 11: 336-344.

29 Gandhi L, Johnson BE. Paraneoplastic syndromes associated with small cell lung cancer. J Natl Compr Canc Netw 2006; 4: 631-638.

30 Mitchell MD, Aggarwal C, Tsou AY, et al. Imaging for the pretreatment staging of small cell lung cancer: a systematic review. Acad Radiol 2016; 8 1047-1056.

31 Zelen M. Keynote address on biostatistics and data retrieval. Cancer Chemother Rep 3 1973; 4: 31-42.

32 Shepherd FA, Crowley J, Van Houtte P, et al. The International Association for the Study of Lung Cancer Lung Cancer Staging Project: proposals regarding the clinical staging of small cell lung cancer in the forthcoming (seventh) edition of the tumor, node, metastasis classification for lung cancer. J Thorac Oncol 2007; 2: 1067-1077.

33 Nicholson AG, Chansky K, Crowley J, et al. The International Association for the Study of Lung Cancer Lung Cancer Staging Project: proposals for the revision of the clinical and pathologic staging of small cell lung cancer in the forthcoming eighth edition of the TNM classification for lung cancer. J Thorac Oncol 2016; 11: 300-311.

34 Hann CL, Rudin CM. Fast, hungry and unstable: finding the Achilles' heel of small-cell lung cancer. Trends Mol Med 2007; 13: 150-157.

35 Sone S, Nakayama T, Honda T, et al. CT findings of early-stage small cell lung cancer in a low-dose CT screening programme. Lung Cancer 2007; 56: 207-215.

36 Salgia R. Diagnostic challenges in non-small-cell lung cancer: an integrated medicine approach. Future Oncol 2015; 11: 489-500.

37 Denton E, Conron M. Improving outcomes in lung cancer: the value of the multidisciplinary health care team. $J$ Multidiscip Healthc 2016; 9: 137-144.

38 Muller J, Putora PM, Schneider T, et al. Handheld single photon emission computed tomography (handheld SPECT) navigated video-assisted thoracoscopic surgery of computer tomography-guided radioactively marked pulmonary lesions. Interact Cardiovasc Thorac Surg 2016; 23: 345-350.

39 National Comprehensive Cancer Network. NCCN Clinical Practice Guidelines in Oncology: Small Cell Lung Cancer 1.2016. Fort Washington, National Comprehensive Cancer Network, 2016.

40 Travis WD. Pathology of lung cancer. Clin Chest Med 2011; 32: 669-692.

41 Travis WD, Brambilla E, Noguchi M, et al. Diagnosis of lung cancer in small biopsies and cytology: implications of the 2011 International Association for the Study of Lung Cancer/American Thoracic Society/European Respiratory Society classification. Arch Pathol Lab Med 2013; 137: 668-684.

42 Fan Z, Schraeder R. The changing pathology of lung cancer. Surg Oncol Clin N Am 2011; 20: 637-653.

43 Travis WD. Advances in neuroendocrine lung tumors. Ann Oncol 2010; 21: Suppl. 7, vii65-vii71. 

cancer, 3rd ed: American College of Chest Physicians evidence-based clinical practice guidelines. Chest 2013; 143: 5 Suppl., e400S-e419S.

45 Vilmann P, Clementsen PF, Colella S, et al. Combined endobronchial and esophageal endosonography for the diagnosis and staging of lung cancer: European Society of Gastrointestinal Endoscopy (ESGE) Guideline, in cooperation with the European Respiratory Society (ERS) and the European Society of Thoracic Surgeons (ESTS). Endoscopy 2015; 47: c1.

46 Ruhstaller T, Roe H, Thürlimann B, et al. The multidisciplinary meeting: an indispensable aid to communication between different specialities. Eur J Cancer 2006; 42: 2459-2462.

47 Powell AA, Schultz EM, Ordin DL, et al. Timeliness across the continuum of care in veterans with lung cancer. $J$ Thorac Oncol 2008; 3: 951-957.

48 Schultz EM, Powell AA, McMillan A, et al. Hospital characteristics associated with timeliness of care in veterans with lung cancer. Am J Respir Crit Care Med 2009; 179: 595-600.

49 Putora PM, Oldenburg J. The Kafkaesque process of cancer diagnosis. J Clin Oncol 2014; 32: 1087-1088.

50 Peddireddy V. Psychological interventions to improve the quality of life in Indian lung cancer patients: a neglected area. J Health Psychol 2016; in press [https://doi.org/10.1177/1359105316650930].

51 van Meerbeeck JP, Fennell DA, De Ruysscher DK. Small-cell lung cancer. Lancet 2011; 378: $1741-1755$.

52 Kvale PA, Selecky PA, Prakash UB, et al. Palliative care in lung cancer: ACCP evidence-based clinical practice guidelines (2nd edition). Chest 2007; 132: 3 Suppl., 368S-403S.

53 Lowenbraun S, Bartolucci A, Smalley RV, et al. The superiority of combination chemotherapy over single agent chemotherapy in small cell lung carcinoma. Cancer 1979; 44: 406-413.

54 Alberto P, Brunner KW, Martz G, et al. Treatment of bronchogenic carcinoma with simultaneous or sequential combination chemotherapy, including methotrexate, cyclophosphamide, procarbazine and vincristine. Cancer 1976; 38: 2208-2216.

55 Bogart JA, Herndon JE II, Lyss AP, et al. 70 Gy thoracic radiotherapy is feasible concurrent with chemotherapy for limited-stage small-cell lung cancer: analysis of Cancer and Leukemia Group B study 39808. Int J Radiat Oncol Biol Phys 2004; 59: 460-468.

56 Roof KS, Fidias P, Lynch TJ, et al. Radiation dose escalation in limited-stage small-cell lung cancer. Int J Radiat Oncol Biol Phys 2003; 57: 701-708.

57 Choi NC, Herndon JE II, Rosenman J, et al. Phase I study to determine the maximum-tolerated dose of radiation in standard daily and hyperfractionated-accelerated twice-daily radiation schedules with concurrent chemotherapy for limited-stage small-cell lung cancer. J Clin Oncol 1998; 16: 3528-3536.

58 Miller KL, Marks LB, Sibley GS, et al. Routine use of approximately 60 Gy once-daily thoracic irradiation for patients with limited-stage small-cell lung cancer. Int J Radiat Oncol Biol Phys 2003; 56: 355-359.

59 Turrisi AT, Kim K, Blum R, et al. Twice-daily compared with once-daily thoracic radiotherapy in limited small-cell lung cancer treated concurrently with cisplatin and etoposide. N Engl J Med 1999; 340: $265-271$.

60 Shahi J, Wright J, Gabos Z, et al. Management of small-cell lung cancer with radiotherapy - a pan-Canadian survey of radiation oncologists. Curr Oncol 2016; 23: 184-195.

61 Movsas B, Moughan J, Komaki R, et al. Radiotherapy patterns of care study in lung carcinoma. J Clin Oncol 2003; 21: 4553-4559.

62 Faivre-Finn C, Snee M, Ashcroft L, et al. CONVERT: an international randomised trial of concurrent chemo-radiotherapy (cCTRT) comparing twice-daily (BD) and once-daily (OD) radiotherapy schedules in patients with limited stage small cell lung cancer (LS-SCLC) and good performance status (PS). http:// meetinglibrary.asco.org/record/122813/abstract Date last accessed: May 26, 2017.

63 Warde P, Payne D. Does thoracic irradiation improve survival and local control in limited-stage small-cell carcinoma of the lung? A meta-analysis. J Clin Oncol 1992; 10: 890-895.

64 Pignon J-P, Arriagada R, Ihde DC, et al. A meta-analysis of thoracic radiotherapy for small-cell lung cancer. $N$ Engl J Med 1992; 327: 1618-1624.

65 Takada M, Fukuoka M, Kawahara M, et al. Phase III study of concurrent versus sequential thoracic radiotherapy in combination with cisplatin and etoposide for limited-stage small-cell lung cancer: results of the Japan Clinical Oncology Group Study 9104. J Clin Oncol 2002; 20: 3054-3060.

66 Corso CD, Rutter CE, Park HS, et al. Role of chemoradiotherapy in elderly patients with limited-stage small-cell lung cancer. J Clin Oncol 2015; 33: 4240-4246.

67 Spiro SG, James LE, Rudd RM, et al. Early compared with late radiotherapy in combined modality treatment for limited disease small-cell lung cancer: a London Lung Cancer Group multicenter randomized clinical trial and meta-analysis. J Clin Oncol 2006; 24: 3823-3830.

68 Fried DB, Morris DE, Poole C, et al. Systematic review evaluating the timing of thoracic radiation therapy in combined modality therapy for limited-stage small-cell lung cancer. J Clin Oncol 2004; 22: 4837-4845.

69 Sun JM, Ahn YC, Choi EK, et al. Phase III trial of concurrent thoracic radiotherapy with either first- or third-cycle chemotherapy for limited-disease small-cell lung cancer. Ann Oncol 2013; 24: 2088-2092.

70 Pijls-Johannesma M, De Ruysscher D, Vansteenkiste J, et al. Timing of chest radiotherapy in patients with limited stage small cell lung cancer: a systematic review and meta-analysis of randomised controlled trials. Cancer Treat Rev 2007; 33: 461-473.

71 De Ruysscher D, Pijls-Johannesma M, Bentzen SM, et al. Time between the first day of chemotherapy and the last day of chest radiation is the most important predictor of survival in limited-disease small-cell lung cancer. $J$ Clin Oncol 2006; 24: 1057-1063.

72 Blackstock AW, Bogart JA, Matthews C, et al. Split-course versus continuous thoracic radiation therapy for limited-stage small-cell lung cancer: final report of a randomized phase III trial. Clin Lung Cancer 2005; 6: $287-292$.

73 De Ruysscher D, Lueza B, Le Pechoux C, et al. Impact of thoracic radiotherapy timing in limited-stage small-cell lung cancer: usefulness of the individual patient data meta-analysis. Ann Oncol 2016; 27: 1818-1828.

74 Brunelli A, Charloux A, Bolliger CT, et al. ERS/ESTS clinical guidelines on fitness for radical therapy in lung cancer patients (surgery and chemo-radiotherapy). Eur Respir J 2009; 34: 17-41.

75 Giuliani M, Sun A, Bezjak A, et al. Utilization of prophylactic cranial irradiation in patients with limited stage small cell lung carcinoma. Cancer 2010; 116: 5694-5699. 
Lee K, Kloecker G, Pan J, et al. The integration of multimodality care for the treatment of small cell lung cancer in a rural population and its impact on survival. Am J Clin Oncol 2015; 38: 448-456.

Langer CJ, Moughan J, Movsas B, et al. Patterns of care survey (PCS) in lung cancer: how well does current US practice with chemotherapy in the non-metastatic setting follow the literature? Lung Cancer 2005; 48: 93-102.

Uno T, Sumi M, Ishihara Y, et al. Changes in patterns of care for limited-stage small-cell lung cancer: results of the 99-01 patterns of care study - a nationwide survey in Japan. Int J Radiat Oncol Biol Phys 2008; 71: 414-419.

Lally BE, Geiger AM, Urbanic JJ, et al. Trends in the outcomes for patients with limited stage small cell lung cancer: an analysis of the Surveillance, Epidemiology, and End Results database. Lung Cancer 2009; 64: 226-231.

Forrest L, McMillan D, McArdle C, et al. An evaluation of the impact of a multidisciplinary team, in a single centre, on treatment and survival in patients with inoperable non-small-cell lung cancer. $\mathrm{Br} J$ Cancer 2005; 93: 977-978.

Price A, Kerr G, Gregor A, et al. The impact of multidisciplinary teams and site specialisation on the use of radiotherapy in elderly people with non-small cell lung cancer (NSCLC). Radiother Oncol 2002; 64: Suppl. 1, 80.

Arriagada R, Le Chevalier T, Borie F, et al. Prophylactic cranial irradiation for patients with small-cell lung cancer in complete remission. J Natl Cancer Inst 1995; 87: 183-190.

Auperin A, Arriagada R, Pignon JP, et al. Prophylactic cranial irradiation for patients with small-cell lung cancer in complete remission. N Engl J Med 1999; 341: 476-484.

Zhang W, Jiang W, Luan L, et al. Prophylactic cranial irradiation for patients with small-cell lung cancer: a systematic review of the literature with meta-analysis. BMC Cancer 2014; 14: 793.

Le Péchoux C, Dunant A, Senan S, et al. Standard-dose versus higher-dose prophylactic cranial irradiation (PCI) in patients with limited-stage small-cell lung cancer in complete remission after chemotherapy and thoracic radiotherapy (PCI 99-01, EORTC 22003-08004, RTOG 0212, and IFCT 99-01): a randomised clinical trial. Lancet Oncol 2009: 10: 467-474.

Schild SE, Foster NR, Meyers JP, et al. Prophylactic cranial irradiation in small-cell lung cancer: findings from a North Central Cancer Treatment Group Pooled Analysis. Ann Oncol 2012; 23: 2919-2924.

Seute T, Leffers P, ten Velde GP, et al. Detection of brain metastases from small cell lung cancer. Cancer 2008; 112: $1827-1834$.

Eaton BR, Kim S, Marcus DM, et al. Effect of prophylactic cranial irradiation on survival in elderly patients with limited-stage small cell lung cancer. Cancer 2013; 119: 3753-3760.

Wolfson $\mathrm{AH}$, Bae K, Komaki R, et al. Primary analysis of a phase II randomized trial Radiation Therapy Oncology Group (RTOG) 0212: impact of different total doses and schedules of prophylactic cranial irradiation on chronic neurotoxicity and quality of life for patients with limited-disease small-cell lung cancer. Int $J$ Radiat Oncol Biol Phys 2011; 81: 77-84.

Sun A, Bae K, Gore EM, et al. Phase III trial of prophylactic cranial irradiation compared with observation in patients with locally advanced non-small-cell lung cancer: neurocognitive and quality-of-life analysis. $J$ Clin Oncol 2011; 29: 279-286.

Gondi V, Paulus R, Bruner DW, et al. Decline in tested and self-reported cognitive functioning after prophylactic cranial irradiation for lung cancer: pooled secondary analysis of Radiation Therapy Oncology Group randomized trials 0212 and 0214. Int J Radiat Oncol Biol Phys 2013; 86: 656-664.

White NH. Long-term outcomes in youths with diabetes mellitus. Pediatr Clin North Am 2015; 62: 889-909.

Jefferson AL. Cardiac output as a potential risk factor for abnormal brain aging. J Alzheimers Dis 2010; 20: 813-821.

Cohen RA, Poppas A, Forman DE, et al. Vascular and cognitive functions associated with cardiovascular disease in the elderly. J Clin Exp Neuropsychol 2009; 31: 96-110.

Kazda T, Jancalek R, Pospisil P, et al. Why and how to spare the hippocampus during brain radiotherapy: the developing role of hippocampal avoidance in cranial radiotherapy. Radiat Oncol 2014; 9: 139.

Gondi V, Mehta M, Pugh S, et al. Memory preservation with conformal avoidance of the hippocampus during whole-brain radiation therapy for patients with brain metastases: primary endpoint results of RTOG 0933. Int $J$ Radiat Oncol Biol Phys 2013; 87: 1186.

Ozawa Y, Omae M, Fujii M, et al. Management of brain metastasis with magnetic resonance imaging and stereotactic irradiation attenuated benefits of prophylactic cranial irradiation in patients with limited-stage small cell lung cancer. BMC Cancer 2015; 15: 589.

Govindan R, Page N, Morgensztern D, et al. Changing epidemiology of small-cell lung cancer in the United States over the last 30 years: analysis of the surveillance, epidemiologic, and end results database. J Clin Oncol 2006; 24: 4539-4544.

The Surgeon General. The Health Consequences of Smoking - 50 Years of Progress: A Report of the Surgeon General. Washington, Dept of Health and Human Services, 2014.

Videtic GM, Stitt LW, Dar AR, et al. Continued cigarette smoking by patients receiving concurrent chemoradiotherapy for limited-stage small-cell lung cancer is associated with decreased survival. J Clin Oncol 2003; 21: 1544-1549.

101 Warren GW, Ward KD. Integration of tobacco cessation services into multidisciplinary lung cancer care: rationale, state of the art, and future directions. Transl Lung Cancer Res 2015; 4: 339-352.

de Hoyos A, DeCamp MM. Surgery for small cell lung cancer. Thorac Surg Clin 2014; 24: 399-409.

Rudin CM, Ismaila N, Hann CL, et al. Treatment of small-cell lung cancer: American Society of Clinical Oncology Endorsement of the American College of Chest Physicians Guideline. J Clin Oncol 2015; 33: 4106-4111.

$4 \mathrm{Xu}$ J, Yang $\mathrm{H}, \mathrm{Fu} \mathrm{X}$, et al. Prophylactic cranial irradiation for patients with surgically resected small cell lung cancer. J Thorac Oncol 2017; 12: 347-353.

5 Lad T, Piantadosi S, Thomas $\mathrm{P}$, et al. A prospective randomized trial to determine the benefit of surgical resection of residual disease following response of small cell lung cancer to combination chemotherapy. Chest Journal 1994; 106: 6 Suppl., 320S-323S.

06 Shepherd F, Evans W, Feld R, et al. Adjuvant chemotherapy following surgical resection for small-cell carcinoma of the lung. J Clin Oncol 1988; 6: 832-838. 
Tsuchiya R, Suzuki K, Ichinose Y, et al. Phase II trial of postoperative adjuvant cisplatin and etoposide in patients with completely resected stage I-IIIa small cell lung cancer: the Japan Clinical Oncology Lung Cancer Study Group Trial (JCOG9101). J Thorac Cardiovasc Surg 2005; 129: 977-983.

108 Schreiber D, Rineer J, Weedon J, et al. Survival outcomes with the use of surgery in limited-stage small cell lung cancer. Cancer 2010; 116: 1350-1357.

109 Wong AT, Rineer J, Schwartz D, et al. Assessing the impact of postoperative radiation therapy for completely resected limited-stage small cell lung cancer using the national cancer database. J Thorac Oncol 2016; 11: $242-248$.

110 Riedel RF, Wang X, McCormack M, et al. Impact of a multidisciplinary thoracic oncology clinic on the timeliness of care. J Thorac Oncol 2006; 1: 692-696.

111 Manapov F, Klöcking S, Niyazi M, et al. Timing of failure in limited disease (stage I-III) small-cell lung cancer patients treated with chemoradiotherapy: a retrospective analysis. Tumori 2012; 99: 656-660.

112 Sunaga N, Tsuchiya S, Minato K, et al. Serum pro-gastrin-releasing peptide is a useful marker for treatment monitoring and survival in small-cell lung cancer. Oncology 1999; 57: 143-148.

113 Okusaka T, Eguchi K, Kasai T, et al. Serum levels of pro-gastrin-releasing peptide for follow-up of patients with small cell lung cancer. Clin Cancer Res 1997; 3: 123-127.

114 Wojcik E, Kulpa JK, Sas-Korczyńska B, et al. ProGRP and NSE in therapy monitoring in patients with small cell lung cancer. Anticancer Res 2008; 28: 3027-3033.

115 Oh H-J, Park H-Y, Kim K-H, et al. Progastrin-releasing peptide as a diagnostic and therapeutic biomarker of small cell lung cancer. J Thorac Dis 2016; 8: 2530. 